\title{
Grupo de Bibliotecas de Arte de España y Portugal
}

Rosario López de Prado

Museo Arqueológico Nacional. Biblioteca

El Grupo de Bibliotecas de Arte de España y Portugal (BAEP) está formado por profesionales de ambos países que trabajan en bibliotecas especializadas en Arte o Historia del Arte, o cuyos fondos pueden considerarse ellos mismos artísticos (manuscritos, fotografías, grabados, etc.). Las instituciones de las que dependen dichas bibliotecas proceden de los más variados ámbitos: museos, academias, universidades, centros de arte y artesanía, galerías, escuelas, sociedades, fundaciones y las Secciones y Servicios de Bellas Artes de las Bibliotecas Nacionales. También forman parte del Grupo aquellas bibliotecas que, sin ser específicamente de arte, poseen colecciones de notable interés especializadas en este campo; es el caso, por ejemplo, de la Biblioteca del Ateneo de Madrid. Sin embargo, no incluyen a las bibliotecas especializadas en música. Aunque nacieron a la sombra de la IFLA, siguen sus directrices y están muy relacionadas con ella, no son un organismo dependiente de esta institución.

\section{Orígenes}

Los profesionales de la documentación de Arte comenzaron ya a mantener reuniones en Madrid desde mediados de los años 80. De allí surgió la conciencia de que era necesario trabajar en equipo y recurrir a actividades cooperativas si se quería estar al nivel profesional que la sociedad exigía. Fruto de estas reuniones fueron un Directorio local de bibliotecas de Arte los primeros intentos de un proyecto -que finalmente no cuajó - para elaborar un catálogo colectivo de publicaciones. Desgraciadamente aquellas reuniones que comenzaron con tan buenas intenciones fueron espaciándose hasta desaparecer. Sin embargo, la idea de la colaboración necesaria ya había prendido.

Años más tarde, el $59^{\circ}$ Congreso de la IFLA, celebrado en Barcelona en agosto de 1993, fue el marco que permitió el renacimiento de las antiguas reuniones: esta vez se integraron bibliotecarios de ambos países, que manifestaron su intención de seguir manteniendo encuentros anuales para tratar asuntos de interés general e intentar establecer canales de colaboración. Aunque al principio la participación fue escasa, cada año se fueron añadiendo más y más bibliotecarios interesados en trabajar conjuntamente con otros compañeros $y$, poco a poco, también se fueron obteniendo frutos tangibles.
En 1994 se celebró el segundo Encuentro en Madrid: esta reunión marcaría de manera definitiva lo que serían los siguientes. Se desarrollaron grupos de trabajo, hubo visitas a bibliotecas de arte y se trabajó sobre un tema determinado, en este caso el tratamiento de los catálogos de exposiciones. En 1995 el Encuentro se celebró en Lisboa, y se orientó hacia los problemas de la indización en historia del arte. En 1996 la reunión tuvo lugar en San Sebastián, donde tomó ya el nombre de IV Encuentro de Bibliotecas de Arte, se formaron grupos de trabajo y se presentaron ponencias formales. Estuvo dedicado a varios temas: el análisis de las colecciones de bibliotecas, la literatura gris, la fotografía y el encabezamiento de materias en el campo del arte. Pero tal vez lo más importante fue que a partir de este Encuentro se comenzó a editar la Hoja Informativa que, dos veces al año, permitía recoger y difundir información sobre las actividades del Grupo.

Valencia fue la sede del $V$ Encuentro, dedicado a las publicaciones periódicas de arte, y de donde surgieron dos nuevos grupos de trabajo sobre Fotografía y Fondo antiguo. Por primera vez se publicaron las Actas, actividad de la que se ocupó la Real Academia de Bellas Artes de San Carlos. EI VI Encuentro tuvo lugar en Barcelona, en las salas del Museu d'Art de Catalunya; asistieron más de sesenta profesionales que discutieron sobre las relaciones entre las Bibliotecas y las instituciones a las que pertenecen. Probablemente, el aspecto más relevante de esta reunión fue que de ella surgió la idea de crear una página web que recogiera las actividades del Grupo y sirviera de foro de debate, canal de comunicación y herramienta de trabajo. Como era de suponer, esta actividad dio lugar a la aparición de un nuevo grupo de trabajo; la página estuvo disponible tres meses más tarde (http://www.mcu.es/BAEP).

Finalmente, se celebró el VII Encuentro en Madrid, los días 21 al 23 de abril de 1999, y estuvo dedicado al tema Sistemas de acceso a la información y difusión artística. En esta ocasión se alternaron ponencias y conferencias, se crearon nuevos grupos de trabajo (dedicados a la Digitalización y a la redacción de Estatutos) y se realizaron visitas profesionales; también se contó con las Actas previamente publicadas en papel y CD-ROM gracias al mecenazgo de la Fundación Marcelino Botín. También merece la pena destacar la cuidada edición de la Guía de bibliotecas de Arte de Madrid elaborada por la Biblioteca Histórica Municipal y publicada por el Ayuntamiento de Madrid con ocasión de esta convocatoria. Pero sin duda lo más destacado fue el elevado número de asistentes que acudieron: casi doscientos. $\mathrm{A}$ partir de este momento se hizo evidente la necesidad de constituirse en asociación formal. La próxima reunión está previsto que se celebre en Coimbra, bajo el lema Integración de Archivos, Museos y Bibliotecas de 
Arte, siguiendo las orientación que marca la Comisión Europea para su $5^{\circ}$ Programa Marco.

\section{Naturaleza y fines}

El Grupo de Bibliotecas de Arte de España y Portugal, nació de acuerdo con las pautas que marca la IFLA para su Sección de Bibliotecas de Arte. Por este motivo tiene vocación de convertirse en foro abierto y ofrecer la posibilidad de participación a todas aquellas entidades y profesionales que estén interesados en el mundo del Arte; también pretende representar a las bibliotecas y organizaciones de ambos países relacionadas con la documentación de las artes visuales, de cualquier clase y sobre cualquier soporte, incluyendo Bellas Artes, Artes Aplicadas, Dibujo y Arquitectura.

La misión principal de este Grupo de profesionales es intentar mejorar la difusión de la información en estas materias. Para ello, trata de facilitar a los usuarios el acceso a la información de arte que se encuentre en bibliotecas de investigación independientes, bibliotecas de museos, bibliotecas de arte vinculadas a instituciones educativas y departamentos de arte de las bibliotecas nacionales, universitarias o públicas. Se ocupa igualmente de la creación, estudio y disfrute de las artes visuales a través de estas bibliotecas y de fomentar las actividades de asociaciones nacionales y regionales de bibliotecas de arte y conservadoras de fuentes visuales. Al mismo tiempo, pretende ser un foro internacional para el libre intercambio de información y de fondos sobre arte, para la formación continua de los bibliotecarios y para lograr los objetivos generales y específicos del programa IFLA, que son los siguientes, tal y como manifiestan en su página web:

\section{Objetivos generales}

- Compartir información y experiencias sobre bibliotecas de arte, publicaciones, bases de datos, redes, catálogos colectivos y actividades que se lleven a cabo en España y Portugal.

- Extender la eficacia y logros del Grupo como foro internacional de información para los bibliotecarios de arte en el que sea posible realizar publicaciones, asistir a conferencias y establecer contactos con otros expertos.

- Proporcionar información sobre el trabajo del Grupo a aquellos profesionales relacionados con la documentación sobre arte y promover la integración de miembros del Grupo para aumentar la efectividad.

\section{Objetivos específicos (Programa a medio plazo)}

- Compartir información y experiencias sobre bibliotecas de arte, publicaciones, bases de datos, redes, catálogos colectivos y actividades diversas.
- Producir al menos dos hojas informativas al año en los momentos más oportunos para conseguir la mayor participación posible en su Encuentro anual

- Extender la eficacia y logros de la Sección como foro internacional de información para los bibliotecarios de arte por medio de publicaciones, conferencias y contactos personales.

- Publicar tan pronto como sea posible las ponencias presentadas en los Encuentros y Jornadas anuales del Grupo.

- Estudiar la posibilidad de establecer enlaces entre los accesos de las bibliotecas del Directorio y sus páginas web, si estas existen. Estudiar la posibilidad de establecer enlaces en línea con los directorios nacionales que contengan más información que la que tenga el Directorio.

- Estudiar la posibilidad de crear una base de datos en línea con información biográfica de artistas nacidos después de 1950.

- Estudiar la posibilidad de crear una bibliografía de los tesauros usados en biblioteconomía de arte, en tantos idiomas como sea posible.

- Proporcionar información sobre el trabajo del Grupo a aquellos profesionales relacionados con la documentación sobre arte y promover la integración de miembros del Grupo para aumentar la efectividad.

- Extender la presencia de la Sección de Bibliotecas de Arte en Internet. Publicar la Hoja Informativa en Internet al mismo tiempo que la copia en papel (1998 y 1999).

- Publicar en Internet las ponencias que se presenten en el Encuentro anual tan pronto como sea posible. Apoyar al Grupo de trabajo en la búsqueda de más información que se pueda cargar en el Web.

\section{Actividades y proyectos}

El Grupo de Bibliotecas de Arte de España y Portugal se ha ido convirtiendo poco a poco en un equipo de profesionales muy activo, que tienen en marcha numerosos proyectos y planean la iniciación de otros a corto y medio plazo, entre los que caben destacar los siguientes:

- Mantenimiento y actualización de la página web del grupo, que sirve de punto de encuentro y comunicación para gran parte de las demás actividades. La página web es el verdadero soporte de actividades y comunicación entre los miembros del grupo, así como instrumento para la proyección externa.

- Creación del Centro de Documentación en Arte, conjunto de medios y herramientas de trabajo disponibles para cualquier profesional que los necesite. 
Consta de recursos propios -Catálogo colectivo de las Bibliotecas de Arte y Catálogos de Bibliotecas -, creados y mantenidos por el mismo equipo de profesionales que forman el Grupo, información de referencia -Directorio BAEP, direcciones de otras bibliotecas e instituciones de interés, bibliografía especializada, directorio de profesionales - que puede ser tanto producto de la actividad profesional de los miembros del grupo como proceder de fuentes externas, y otros instrumentos de trabajo: tesauros multilingües, enlaces de interés, selección de normas, etc.

- Creación y mantenimiento de un grupo de discusión, y lista de distribución de correo, que permitirá una participación más directa y rápida y facilitará el intercambio de experiencias, opiniones y actividades.

- Creación de sistemas de acceso a bases de datos especializadas. También a través de la página web, se pretende localizar e incorporar aquellas bases de datos que guarden información de especial relevancia para el mundo del arte. A más largo plazo, se intenta diseñar un tipo de interface consistente en la consulta de estas bases de datos de una manera sencilla para el usuario.

- Establecimiento de las condiciones y canales para facilitar un sistema ágil de préstamo interbibliotecario y canje de publicaciones especializadas. Una de las actividades con mayor demanda entre las bibliotecas de Arte es el intercambio de publicaciones, sea en préstamo o en canje. La página web y el correo electrónico -así como otros medios más tradicionales cuando estos no estén disponibleshacen posible que los fondos de cada una de las bibliotecas del grupo estén disponibles para cualquier usuario interesado en ellos de forma rápida y económica.

- Sistema de localización y difusión de convocatorias y novedades que afecten al ámbito profesional de las bibliotecas de Arte. Una vez más, la página web actúa como canal de comunicación y difusión de la información que interesa a los miembros del Grupo, recogiendo las convocatorias y demás novedades que puedan afectarles y poniéndolas a su disposición a través de Internet, directamente o mediante enlaces.

- Apoyo y asesoramiento profesional a los miembros del Grupo cada vez que lo precisen. Esta función es actualmente una de las más solicitadas. Con frecuencia los profesionales que trabajan en bibliotecas de Arte se enfrentan a problemas que no son nuevos para otros colegas; gracias al Directorio de Bibliotecas y al tablón de anuncios de la página web, pueden ponerse en contacto entre sí y solicitar ayuda y orientación en situaciones determinadas.
Algunas bibliotecas ofrecen asesoramiento; otras proporcionan plantillas para elaborar instrumentos de gestión; las hay que actúan como intermediarias entre terceras; la mayoría están dispuestas a recibir visitantes y explicarles la forma en que han resuelto determinados problemas. En todos los casos las experiencias y trabajos que se han llevado a cabo por una institución están a disposición de las otras

\section{Conclusión}

El Grupo de Bibliotecas de Arte de España y Portugal se ha convertido en un equipo de profesionales muy activos, que, partiendo de una situación de aislamiento, están desarrollando una serie de proyectos de cooperación cada vez más amplia. Los miembros de las BAEP están convencidos de que el trabajo conjunto y la cooperación es la única forma posible que tienen las bibliotecas especializadas de atender las demandas de sus usuarios y garantizar el acceso de estos a la información que precisan. La especialización, incluso dentro del mismo campo, es cada día más marcada, las publicaciones cada vez más abundantes y las necesidades de los lectores más y más diversas y complejas. Ninguna institución puede, por sí misma, garantizar una respuesta correcta a todas las demandas de sus usuarios.

Además, las bibliotecas de Arte se enfrentan a una situación muy compleja. De entrada, la mayoría pertenece a instituciones que a menudo constriñen su desarrollo y lo determinan; arrastran un pasado de aislamiento $y$, en muchos casos, un presente de carencias; están obligadas a responder a dos clases de demandas bien diferentes, la de investigadores y la divulgativa; $y$, finalmente, con los medios de siempre deben hacer frente a un aumento constante de requerimientos. Por todo ello, los profesionales que trabajan en estas bibliotecas son conscientes de que sólo con la cooperación interbibliotecaria y el apoyo mutuo estarán en condiciones de dar respuestas satisfactorias a las cuestiones que se les plantean.

El Grupo de Bibliotecas de Arte de España y Portugal no es más que la consecuencia de todas estas circunstancias. Por eso nació de forma espontánea, sin responder a un plan previsto de antemano, por eso se desarrolló año tras año y por eso se ha convertido en el punto de referencia de la documentación de Arte. Por eso, más que un árbitro que medie entre conflictos o, menos aún, un mecanismo de reglamentación, pretende ser -y de hecho ya lo es -, un mediador entre iguales, un organismo que favorezca la participación, un foro en el que cotejar y analizar nuestras ideas y donde confrontar nuestras experiencias $y$, en definitiva, un motor de cooperación entre profesionales convencidos de que sólo actuando juntos pueden ofrecer lo mejor. 